Research Article

\title{
Reliability Analysis of Loess Cave Dwellings Based on Fuzzy Failure Criterion
}

\author{
Pinggong Guo \\ Department of Civil and Traffic Engineering, Henan University of Urban Construction, Pingdingshan 467036, China \\ Correspondence should be addressed to Pinggong Guo; pgguo@qq.com
}

Received 27 January 2021; Revised 31 July 2021; Accepted 6 August 2021; Published 17 August 2021

Academic Editor: Leandro F. F. Miguel

Copyright (c) 2021 Pinggong Guo. This is an open access article distributed under the Creative Commons Attribution License, which permits unrestricted use, distribution, and reproduction in any medium, provided the original work is properly cited.

The reliability of loess cave dwellings based on fuzzy failure criterion is researched to analyze the influence of fuzzy set, membership function, and different combinations of random variables. Due to the strength reduction method, the basic failure criterion is established, the fuzzy property of failure criterion is characterized by fuzzy set and membership function, and the performance function of loess cave dwellings is expressed by a quadratic polynomial without cross terms. Reliability is analyzed with different random variable combinations. The reliability research of loess cave dwellings in Shan Plateau, Henan province, China, shows that the loess property in this area is suitable for loess cave dwelling construction and the reliability index of loess cave dwellings is high, which will be decreased when considering the fuzzy failure criterion and will be increasing sharply when the small cave leg width is improved to average value.

\section{Introduction}

Loess cave dwellings are "green houses". The main kinds of loess cave dwellings are cliff caves and ground caves. Cliff caves are distributed along the contour lines on the mountain (Figure 1), and ground caves form an underground village (Figure 2).

Loess cave dwellings are supported by an original soil arches without beam or other lining, but they can survive over hundreds of years, even in the district where an earthquake is in high possibility. These reveal that the mechanical principle of loess cave dwellings is reasonable, the construction is ingenious, and the reliability is high.

To evaluate the reliability of loess cave dwellings, our research team surveyed and drew hundreds of loess cave dwellings in Shan Plateau in Henan Province, China, which afford the basic data for the probabilistic analysis.

The reliability of loess cave dwellings has been never researched, and there is not any code about it. For any probabilistic problem, the first step is the definition of the limit state. However, the limit state of loess cave dwellings is unknown. Factor of safety (Fs) is regularly used in geotechnical problems, especially in slope: when Fs is 1 , the system is at the limit state, and if Fs is greater than 1, the system is safe; otherwise, there is failure. In this paper, the strength reduction method is used to solve Fs. However, there is still a question of Fs which is directly responsible for the failure probability of geotechnical systems; when Fs is greater than 1, the system may be not safe. There is no clear dividing line between reliable and unreliable, and defining a system as fully failed or functioning is not extensively acceptable, and thus, the fuzzy state assumption should be used to replace the binary state assumption [1]. State's fuzziness means that the failure criterion is fuzzy. Reliability analysis of loess cave dwellings based on fuzzy failure criterion is more reasonable. Bagheri et al. suggested fuzzy reliability analysis using genetic optimization algorithm combined by adaptive descent chaos control [2]. Pramanik assessed the bearing capacity of shallow foundation using fuzzy set theory [3]. Hamidane et al. analyzed the reliability with epistemic uncertainties [4]. These research studies are not concerned with the fuzzy failure criterion.

For probabilistic analysis, another basic problem is the choice of random variables. It should be noticed that the 


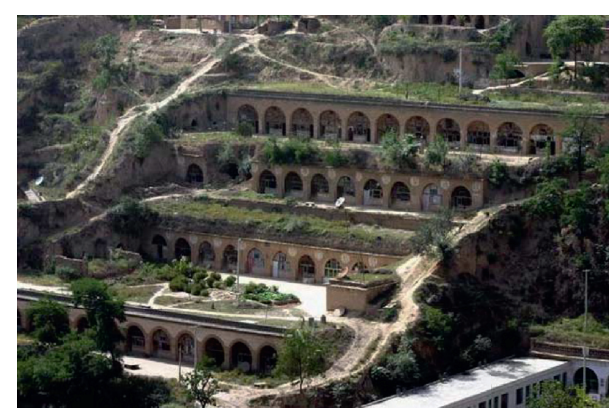

Figure 1: Cliff cave dwellings.

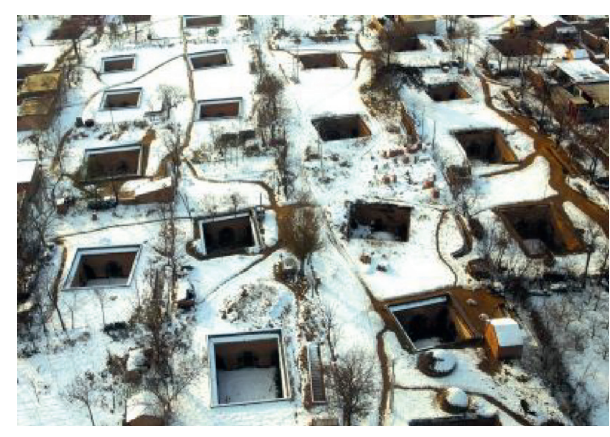

Figure 2: Sketch of underground village.

reliability of all loess cave dwellings in Shan Plateau in Henan Province, China, is researched in this paper. Thus the mechanical property parameters of loess in this area should be considered as random variables. In addition, the geometric size of loess cave dwellings that have great influence on reliability cannot be neglected.

Another problem is the performance function of system. The performance function of loess cave dwellings is unknown, to solve the failure probability, Monte Carlo simulation (MCS) [5], and response surface method (RSM) can be used [6]. For loess cave dwellings, MCS means that millions of finite-element models should be set up, which is not possible. RSM is an efficient way to solve the failure probability of loess dwellings.

In this paper, strength-reduced method and response surface method are used to solve the reliability of loess cave dwellings in Shan Plateau in Henan Province, China, which is based on fuzzy failure criterion. The process of strengthreduced method is in Part 2, which is reducing the strength of soil, until the failure state is reached.

\section{Fs Based on Strength Reduction Method}

After Zienkiewicz suggested the shear strength reduction coefficient [7], the safety factor has been widely used on the basis of strength reduction method, especially in the stability analysis of slop [8]. The definition of shear strength reduction coefficient is that, without the change of load, the ratio of the maximum shear strength that the soil can afford and the real shear stress in the soil. The basic principle of the theory is that both the cohesion stress $c$ and internal friction angle $\varphi$ are divided by the reduction coefficient $F$, new $c$ ' and $\varphi^{\prime}$ are get, and the equation is

$$
c^{\prime}=\frac{c}{F}, \phi^{\prime}=\arctan \left(\frac{\tan \phi}{F}\right) .
$$

The new parameters are used in the FEM, if the system is stable, then use equation (1) again, until the system is failed, the critical value of $F$ is Fs when the system is at the limit state. But the limit states of the systems are various; now there are mainly three kinds [9]. First, the plastic zone cuts through one face; second, the displacement of the characteristic point changes greatly; third, the FEM (finite-element method) calculation is not converged.

Loess cave dwellings have many parts, such as cave span, cave leg that means the loess between two caves, cover soil, and so on, as shown in Figure 3.

The cave in the middle is most likely to damage because the left and right sides are cave legs. Using Abaqus analysis, it is found that the vertical displacement of the point $\mathrm{A}$ (as shown in Figure 3), that is, the top point of the cave in the middle, is the biggest. When the soil mechanical parameters are the average values and the geometrical parameters of loess cave dwellings are also the average values, which are shown in Tables 1 and 2, the relationship between the vertical displacement of the point $A$ and strength reduction coefficient $\mathrm{F}$ is shown in Figure 4. Displacement upward is positive. In Figure 4, when F increases from 1.58 to 1.60, the vertical displacement downward increases from 48 to $98 \mathrm{~mm}$, which changes sharply. Therefore, 1.58 is factor of safety (Fs).

For the same finite-element model, with the increasing of $F$, the developing of the plastic zone is shown in Figure 5. When $F$ is 1.58, all parts of the cave leg are in the plastic zone, so 1.58 is the factor of safety (Fs). For loess cave dwellings, the first and second limit state criteria are the same in nature.

\section{Fuzzy Failure Criterion of Loess Cave Dwellings}

3.1. Basic Failure Criterion of Loess Cave Dwellings. At present, there is no standard or code about failure or not of loess cave dwellings. ESF (excess safety factor) is introduced as a failure criterion in this paper. ESF has properties, when ESF is equal to zero, loess cave dwellings are in ultimate bearing capacity, and if ESF is greater than zero, loess cave dwellings are reliable, if not it is unreliable. Suppose that the performance function of loess cave dwellings is given by

$$
Z=g\left(X_{1}, X_{2}, \ldots, X_{n}\right) \text {. }
$$

$X_{1}, X_{2}, \ldots, X_{n}$ are random variables. Thus ESF and $Z$ are equal. (3).

$F_{S}$ (safety factor) and ESF have the relation as equation

$$
\mathrm{ESF}=F_{S}-1
$$

3.2. Fuzzy Failure Criterion of Loess Cave Dwellings. It is accepted that loess cave dwellings are unreliable when ESF is less than zero, but it is doubtful that loess cave dwellings are reliable when the ESF is greater than zero. For example, loess cave dwellings may not be safe when ESF is 0.01 . There is a 


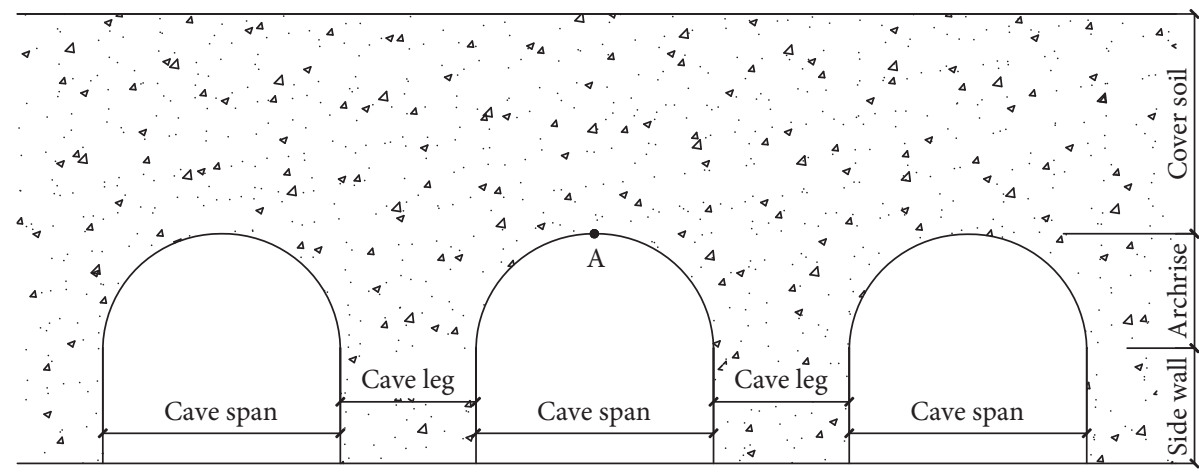

Figure 3: Sketch map of loess cave dwellings.

TABLE 1: Average mechanical parameters of loess.

\begin{tabular}{lcccc}
\hline $\mathrm{E}(\mathrm{MPa})$ & $\mu$ & Density $\left(\mathrm{kN} / \mathrm{m}^{3}\right)$ & Cohesion $(\mathrm{kPa})$ & Internal friction angle $\left(^{\circ}\right)$ \\
\hline 51.5 & 0.25 & 13.5 & 51.8 & 28.1 \\
\hline
\end{tabular}

TABLE 2: Average geometry parameters of loess cave dwellings.

\begin{tabular}{lcccc}
\hline Cave leg width $(\mathrm{m})$ & Cave span $(\mathrm{m})$ & Height of side wall $(\mathrm{m})$ & Archrise $(\mathrm{m})$ & Cover soil depth $(\mathrm{m})$ \\
\hline 1.76 & 3.08 & 1.50 & 1.50 & 2.87 \\
\hline
\end{tabular}

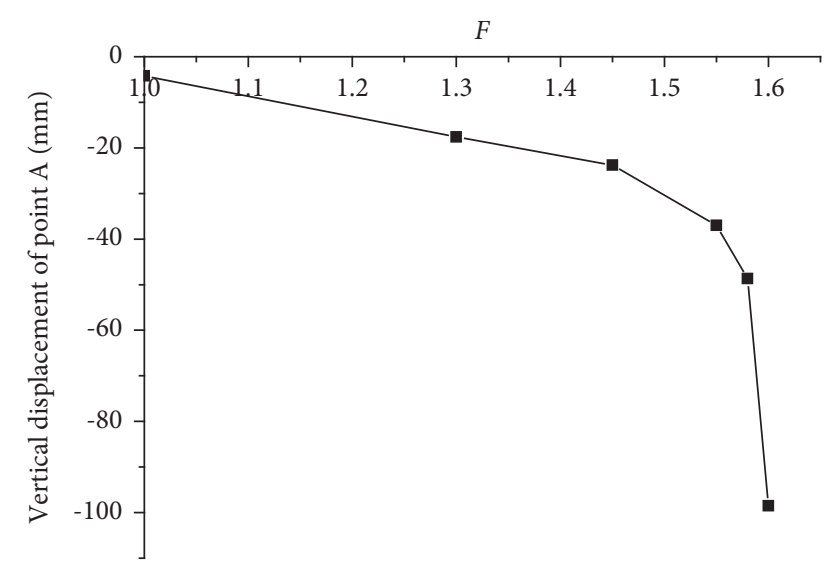

FIgURE 4: Relation between vertical displacement of characteristic point and strength reduction factor.

transition region between failure and reliable, as shown in Figure 6.

In Figure $6, f_{Z}(z)$ is the probabilistic density function, [0, $a$ ] is a fuzzy set, and $\mu_{Z}$ is the average value of $Z$. The width of a fuzzy set is expressed by the ratio of the set width and the average value of $Z$. The ratio is expressed by $w$. According to engineering experience, the range of $w$ is $[0,0.3]$, and $a$ is equal to $w \mu_{Z}$, so the fuzzy set is $\left[0, w \mu_{Z}\right]$.

Such a set is characterized by a membership (characteristic) function which assigns to each object a grade of membership ranging between zero and one [10]. The common form of membership function is ladder shape and ridge shape.

The ladder form membership function of $Z$ is

$$
\mu_{\underline{E}}(z)= \begin{cases}1 & z<0 \\ \frac{a-z}{a} & 0 \leq z \leq a \\ 0 & z>a\end{cases}
$$

The ridge form membership function of $Z$ is

$$
\mu_{\underline{E}}(z)= \begin{cases}1 & 0 \\ \frac{1}{2}-\frac{1}{2} \sin \left[\frac{\pi}{a}\left(z-\frac{a}{2}\right)\right] & 0 \leq z \leq a \\ 0 & z>a\end{cases}
$$

In equations (4) and (5), $\mu_{E}(z)$ is the membership degree. The figures of two kinds of membership function are shown in Figure 7.

Two kinds of membership functions are all decreasing functions, which mean that with the increasing of " $Z$ ", the failure probability of the structure system is approaching to 0 , and the structure system is close to "reliable". At the same value of " $Z$ ", the membership degrees of two kinds of membership functions are very close.

Thus the fuzzy failure probability is

$$
\begin{aligned}
p_{f} & =\int_{-\infty}^{\infty} \mu_{\underline{E}}(z) f_{Z}(z) \mathrm{d} z=\int_{-\infty}^{a} \mu_{\underline{E}}(z) f_{Z}(z) \mathrm{d} z \\
& =\int_{-\infty}^{0} f_{Z}(z) \mathrm{d} z+\int_{0}^{a} \mu_{\underline{E}}(z) f_{Z}(z) \mathrm{d} z .
\end{aligned}
$$




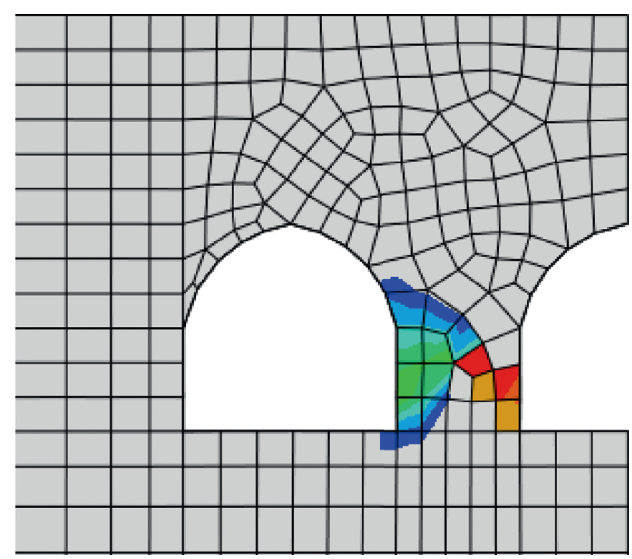

$F=1.20$

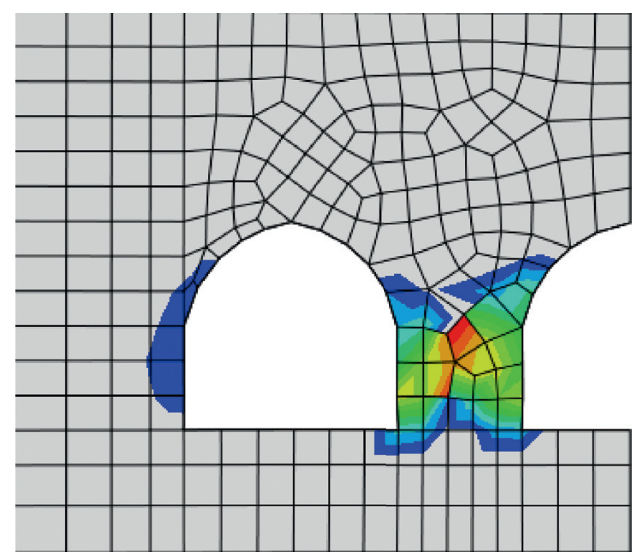

$F=1.45$

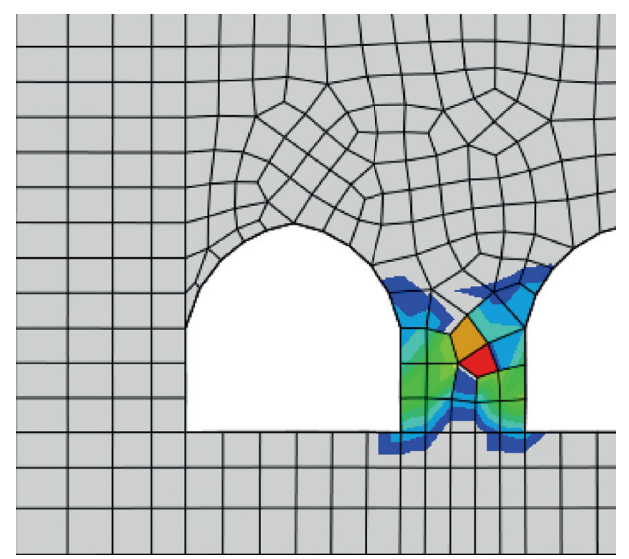

$F=1.30$

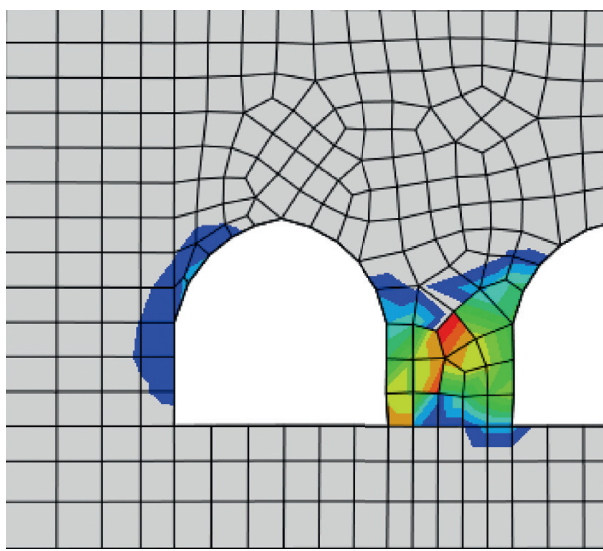

$F=1.58$

FIgURE 5: Relation between the development of plastic zone and strength reduction factor.

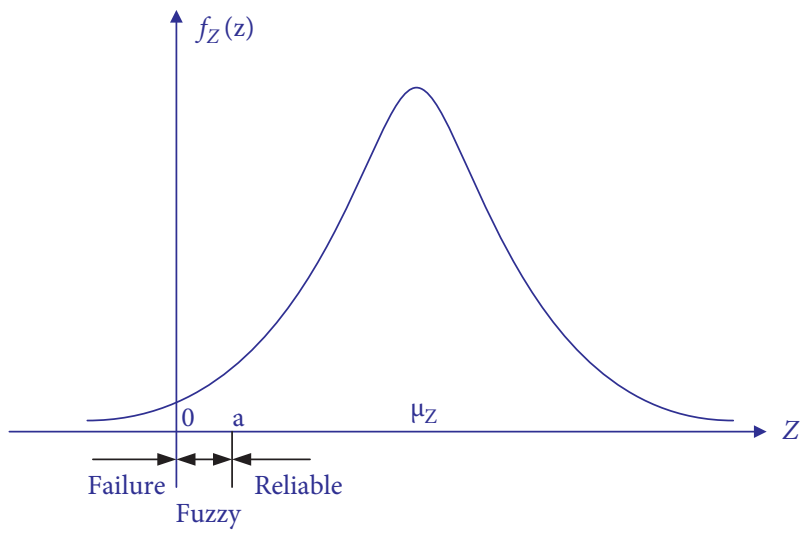

FIgURe 6: Probabilistic density function of loess cave dwellings.

The random variables of loess cave dwellings are normal distribution, so $Z$ is also normal distribution approximately, and its probabilistic density function is

$$
f_{Z}(z)=\frac{1}{\sqrt{2 \pi} \sigma_{Z}} \exp \left[-\frac{1}{2}\left(\frac{z-\mu_{Z}}{\sigma_{Z}}\right)^{2}\right] .
$$

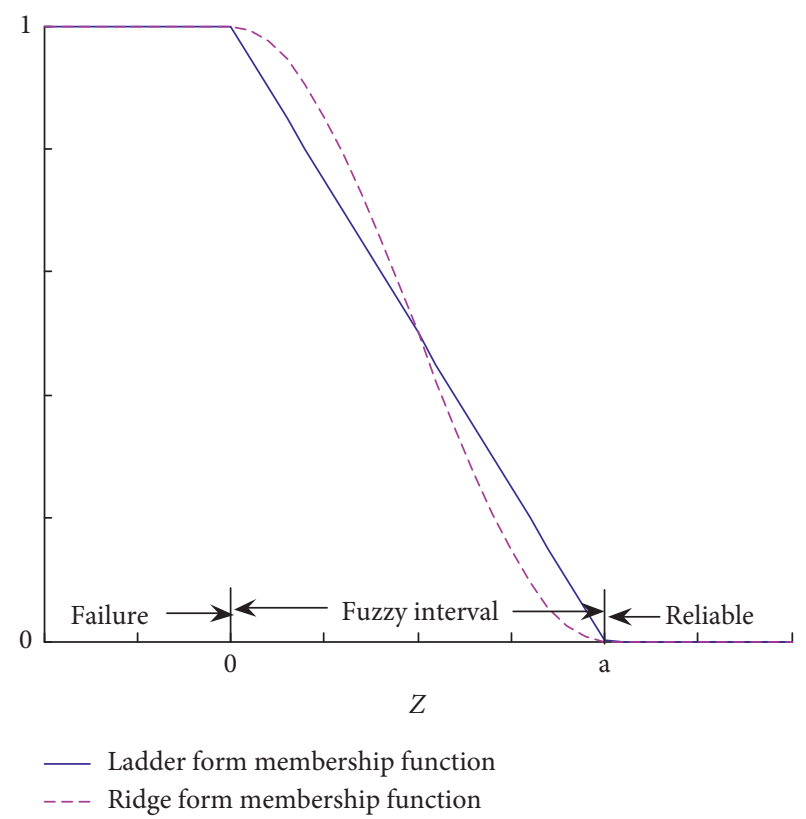

Figure 7: Figures of two kinds of membership function. 
In equation (7), $\mu_{Z}$ and $\sigma_{Z}$ are the average value and standard deviation of $Z$.

The fuzzy reliability index is

$$
\beta=\Phi^{-1}\left(1-p_{f}\right)
$$

In equation (8), $\mu_{E}(z)$ is the inverse function of the normal distribution function.

Based on the advanced first-order second-moment method, we assumed that $x^{*}=x_{1}^{*}, x_{2}^{*}, \ldots, x_{n}^{*}$ is the checking point, which means $g\left(x_{1}^{*}, x_{2}^{*}, \ldots, x_{n}^{*}\right)=0$; therefore, the average value $\mu_{Z}$ and standard deviation $\sigma_{Z}$ of $Z$ are

$$
\begin{aligned}
& \mu_{Z}=g\left(x^{*}\right)+\sum_{i=1}^{n} \frac{\partial g\left(x^{*}\right)}{\partial X_{i}}\left(X_{i}-x_{i}^{*}\right), \\
& \sigma_{Z}=\sqrt{\sum_{i=1}^{n}\left[\frac{\partial g\left(x^{*}\right)}{\partial X_{i}}\right]^{2} \sigma_{X_{i}}^{2}}
\end{aligned}
$$

In the condition of regular reliability analysis, the failure probability of loess cave dwellings is

$$
p_{f}^{0}=\int_{-\infty}^{0} f_{Z}(z) \mathrm{d} z
$$

Thus the increased failure probability based on fuzzy failure criterion is

$$
\Delta p_{f}=\int_{0}^{a} \mu_{\underline{E}}(z) f_{Z}(z) \mathrm{d} z
$$

The reliability index based on fuzzy failure criterion is smaller than the basic failure criterion, and the decreasing degree is related to the fuzzy set $[0, a]$ and the form of membership function, which will be discussed in this paper.

\section{The Fit of Loess Cave Dwellings' Performance Function}

4.1. Selection of Random Variables. The loess cave dwellings are in loess, and the unique property of the loess is a guarantee for reliability. The selected random variables are cohesion and internal friction angle, both of which are normal distributions, and the standard deviations are 0.1 times their average value. Cohesion and internal friction angle are the first group random variables in the paper to investigate whether the loess in this region is suitable for cave dwelling construction or not.

The researching targets of this paper are all loess cave dwellings in Shan Plateau. Not only the mechanical parameters but also every part's geometric parameters have great influence on reliability. Among the geometric parameters, cave span and cave leg width have an important influence on the reliability, which are also selected as random variables. Cohesion, internal friction angle, cave span, and cave leg width are the second group random variables in this paper, to discuss the reliability of cave dwellings with the coupling of mechanical parameters and geometric parameters, and the rationality of geometric parameters selection. The average values of geometric parameters are listed in Table 2. The parameters of cave span and cave leg width are normal distribution, and the standard deviations are 0.319 and $0.173 \mathrm{~m}$. The deviation coefficient of cave leg width is 0.18 that is bigger than the cave span which is 0.056 .

Regarding the first group of random variables, the inputting parameters of each round FEM analysis are cohesion and internal friction angle. For the second group of random variables, besides cohesion and internal friction angle, the inputting parameters also include cave span and cave leg width, that is to say, every finite-element model of loess cave dwellings should be set up again which is a hard job and that is the reason Monte Carlo Simulation cannot be used.

4.2. The Fit of Performance Function. Quadratic polynomial response surface function is used to fit the performance function. The higher-degree polynomial is not often used because of conception and calculation. To minimize the calculation of FEM analysis, the form of the response surface function should be simple, and the undetermined coefficients should be less, so a quadratic polynomial without cross terms is selected, the form of which is expressed as equation (12). Kriging interpolation model is not used because sensitive coefficients can be easily obtained from quadratic polynomial response surface function.

$$
Z=g\left(X_{1}, X_{2}, \ldots, X_{n}\right)=a+\sum_{i=1}^{n} b_{i} X_{i}+\sum_{i=1}^{n} c_{i} X_{i}^{2} .
$$

In equation (12), $a, b_{i}$, and $c_{i}$ are undetermined coefficients. The solution of the response surface function is transformed to the solution of undetermined coefficients in equation (12). To solve the undetermined coefficients, a series of testing points should be determined, and the corresponding ESF should be worked out. The testing points are the central composite designs whose points are only on the axis of coordinates. The testing points are shown in Figure 8 when there are only two random variables.

In Figure $8,\left(T_{X 1}, T_{X 2}\right)$ is the testing central point; $\sigma_{X 1}$, $\sigma_{X 2}$ are the standard deviation of random variables of $X_{1}, X_{2}$; and $h>0$ is an arbitrary factor. To get the checking point and reliability index, many rounds of FEM calculation are needed, and the FEM model is set up due to the testing points shown in Figure 8. It is important to be explained that the central point is different in every round, and its tendency is close to the checking point gradually. In the first round, $h$ is 3 , after that it is 1 .

During the calculation of every round of FEM analysis, the solution of the response surface function is followed by steps as follows: (1) the FEM model is set up at the testing points, and the corresponding ESF can be found. (2) Solving the linear equations, the undetermined coefficients $a, b_{i}$, and $c_{i}$ are obtained and then the response surface function is known.

After the solution of the response surface function, the reliability index, and checking point can be obtained following the advanced first-order second-moment method. 


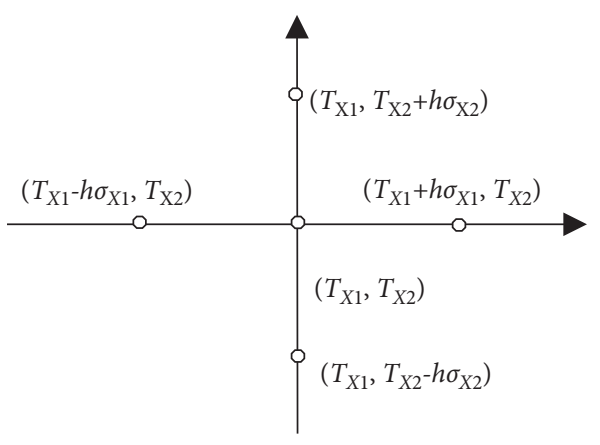

Figure 8: Testing points in two-dimensional random plane.

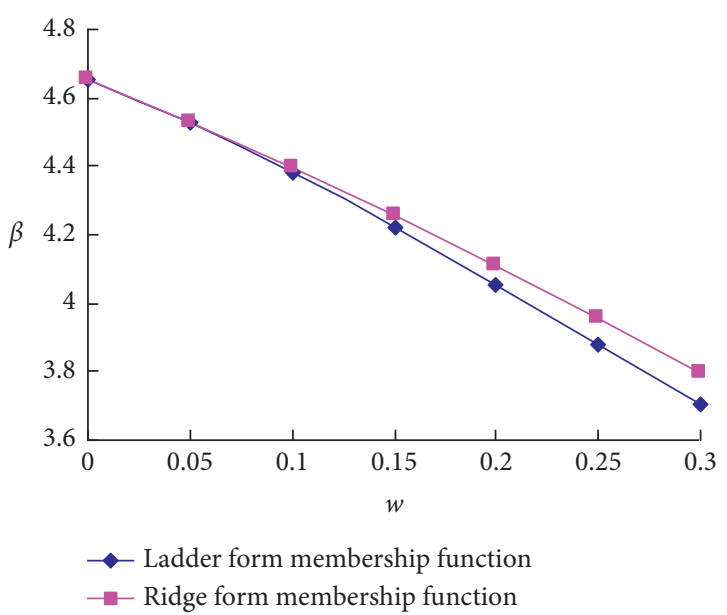

Figure 9: Relation between $\beta$ and $w$ (random variables of mechanical parameters).

TABLE 3: Targets reliability index of the ultimate state of bearing capacity.

\begin{tabular}{lccc}
\hline Failure type & First level & $\begin{array}{c}\text { Level of safety } \\
\text { Second level }\end{array}$ & Third level \\
\hline Ductility & 3.7 & 3.2 & 2.7 \\
Brittle & 4.2 & 3.7 & 3.2 \\
\hline
\end{tabular}

When the module of checking points satisfies equation (13), no more FEM model needs to be set up.

$$
\frac{\left\|x_{(n)}^{*}\right\|-\left\|x_{(n+1)}^{*}\right\|}{\left\|x_{(n+1)}^{*}\right\|}<0.01 .
$$

In equation (13), $\mu_{E}(z)$ is the checking point in round $n$ and $\mu_{\underline{E}}(z)$ is the checking point of round $n+1$, both of which are random vectors.

\section{The Reliability of Loess Cave Dwellings}

5.1. In the Case of Random Variables of Mechanical Parameters. When the random variables are only cohesion and internal friction angle, with different membership functions, the relation between the reliability index $\beta$ and the ratio $w$ of fuzzy set is shown in Figure 9.

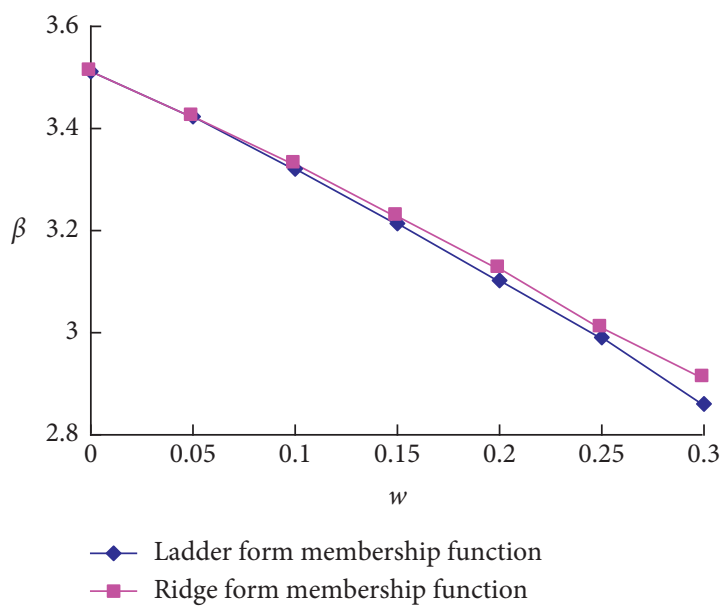

Figure 10: Relation between $\beta$ and $w$ (coupling of mechanical and geometry parameters).

The reliability index has no relationship with the form of membership function when the width ratio $w$ is 0 , which means the fuzzy failure criterion degenerates to the basic failure criterion, when the reliability index is the highest and the failure probability is about one in a million. With the increase of $w$, the fuzzy reliability index is diminishing, no matter which form of membership function. The reliability index is still greater than 3.6 when $w$ is at the biggest value of 0.3 . According to the target reliability index of the ultimate state of bearing capacity (shown in Table 3 ) in Chinese code of "Unified standard for reliability design of building structures ", the reliability of loess cave dwellings is close to brittle failure's second level.

The result shows that the soil property of Shan plateau is very suitable for loess cave construction, which is also the reason loess cave dwellings are extensive in Shan plateau.

With the same $w$, reliability index obtained by the ridge form membership function is a little bigger than the ladder form. The form of membership function influences reliability little.

5.2. In the Case of Random Variables of Mechanical and Geometric Parameters. When the second group of random variables mechanical and geometric parameters is used, with different membership function, the relation between reliability index and ratio $w$ of fuzzy set is shown in Figure 10 .

The reliability index has no relationship with the form of membership function when width ratio $w$ is 0 which means the fuzzy failure criterion degenerate to basic failure criterion, and the reliability index is high which is between brittle failure's second level and third level. With the increase of $w$, fuzzy reliability index is diminishing, no matter which form of membership function. If the failure of loess cave dwellings are treated as brittle failure and its lowest target reliability index is 3.2, it is satisfied when $w$ is less than 0.15 , but not if $w$ is increasing.

Comparing Figures 9 and 10, the reliability index with the second group of random variables is much lesser than the first group. When the geometric parameters are changed 


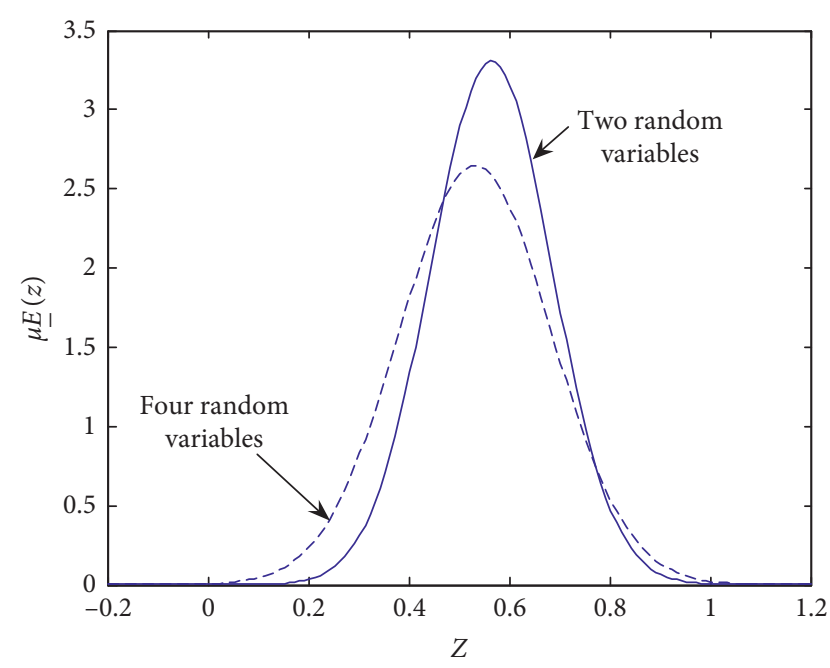

FIgURE 11: Probabilistic density function with different group of random variables.

from average value to random variables, the reliability index decreases quickly, which means that the discreteness of geometric parameters is great. Based on statistical data, the deviation coefficient of cave leg width is close to $20 \%$, which is the main reason why reliability decreases quickly.

Both Figures 9 and 10 show that the form of membership function influences reliability little.

\subsection{Probabilistic Density Function with Different Random} Variables. When the random variables are different, the performance function and probabilistic density function of loess cave dwellings are different. The probabilistic density functions are shown in Figure 11. This paper focuses on four parameters (cohesion, cave leg width, internal friction angle, and cave span), which have the most influence on the reliability of cave dwellings, other aspects such as the entrance shape of cave dwellings has smaller influence, and changes little.

In Figure 11, "two random variables" is the first group of random variables, and "four random variables" is the second group of random variables. The average value of $Z$ under four random variables is smaller than two random variables, but the standard deviation of $Z$ under four random variables is bigger than two random variables. The probability of $Z<0$ is very small with two and four random variables. With the fuzzy set $[0, a]$ and the same membership function, the value of equation (11) of four random variables is much bigger than two random variables, so the reliability index decreases quickly. No matter two or four random variables, the value of equation (11) is bigger than that of equation (10) and much bigger with the increasing of $a$; therefore, the fuzzy interval has a great influence on the reliability of loess cave dwellings.

5.4. Checking Points and Sensitivity Coefficient. When $w$ is 0 , the checking points can be found by the advanced firstorder second-moment method. When (cohesion and

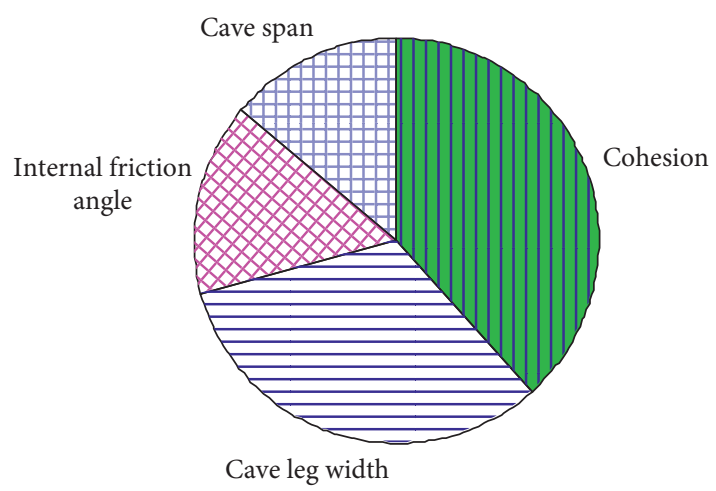

FIGURE 12: Pie graph of sensitivity coefficients.

internal friction angle) are random variables, the checking point is $\left(29.82 \mathrm{kPa}, 22.7^{\circ}\right)$. When cohesion, internal friction angle, cave leg width, and cave span are random variables, the checking point is $38.17 \mathrm{kPa}, 25.1^{\circ}, 1.05 \mathrm{~m}$, and $3.25 \mathrm{~m}$. The checking point about mechanical parameters is increasing when the geometric parameters and random variables are added. It means that the mechanical parameters should be increased if keeping the same reliability.

In the process of advanced first-order second-moment method, the sensitivity coefficient can be obtained as follows:

$$
\alpha_{X_{i}}=-\frac{\sum_{i=1}^{n}\left(\partial g_{X}\left(x^{*}\right) / \partial X_{i}\right) \sigma_{X_{i}}}{\sqrt{\sum_{i=1}^{n}\left[\partial g_{X}\left(x^{*}\right) / \partial X_{i}\right] \sigma_{X_{i}}^{2}}} .
$$

In equation (15), $\alpha_{X i}$ is the sensitivity coefficient of random variable $X_{i}$. The absolute value of $\alpha_{X i}$ is bigger, and the influence of random variable $X_{i}$ on reliability is greater. If $\alpha_{X i}$ is negative, $X_{i}$ is the provider of bearing capacity, otherwise, $X_{i}$ is load.

Sensitivity coefficient pie chart of parameters is shown in Figure 12 with the second group of random variables and $w=0$. From Figure 12, it can be seen that cohesion and cave leg width have a main influence on the reliability index of loess cave dwellings, and the influence of cohesion is little bigger than the cave leg width. Internal friction angle and cave span have a small influence on reliability index, and they almost have the same influence. Cave span has small influence which is parallelism to its small deviancy.

The influence of cohesion on the reliability of cave dwellings in this area is constant. To promote the reliability, improving the cave leg width that is smaller than $1.76 \mathrm{~m}$ to the average value is a good method, and the reliability index will increase quickly.

\section{Conclusions}

In this paper, ESF based on strength reduction method is the basic failure criterion of loess cave dwellings, and the performance function is fit by a quadratic polynomial without cross terms. The reliability index is discussed with different fuzzy sets, membership functions, and random variables combinations. Conclusions are as follows: 
(1) ESF can describe the safety of loess cave dwellings on the whole, and it is reasonable when ESF is used as a basic failure criterion. It is necessary to bring in the fuzzy failure criterion based on ESF.

(2) The mechanical property of loess in Shan Plateau, Henan Province, is suitable for cave dwellings construction. Especially the high cohesion is a natural advantage, and the reliability of loess cave dwellings in this area is high.

(3) The reliability is decreasing with the fuzzy failure criterion, especially when the width of fuzzy set is bigger.

(4) The form of membership function influences the reliability little, so the ladder form membership function is simple and safe that can be used in the analysis of loess cave dwellings later.

(5) With the numbers increasing of random variables, the reliability index will decrease.

(6) Cave leg width has essential influence on reliability, improving small cave leg width to an average value is a good method to promote reliability.

(7) When the reliability index of the loess cave dwellings is smaller than 3.2 (see details in Table 3), reinforced measures should be taken.

\section{Data Availability}

The data used to support the findings of this study are included within the article.

\section{Conflicts of Interest}

The author declares that there are no conflicts of interest.

\section{References}

[1] K.-Y. Cai, C.-Y. Wen, and M.-L. Zhang, "Fuzzy states as a basis for a theory of fuzzy reliability," Microelectronics Reliability, vol. 33, no. 15, pp. 2253-2263, 1993.

[2] M. Bagheri, K. Behrooz, and Z. Shun-Peng, "Fuzzy reliability analysis using genetic optimization algorithm combined with adaptive descent chaos control," Part A Civil Engineering, vol. 6, p. 2, 2020.

[3] R. Pramanik, D. K. Baidya, and N. Dhang, "Reliability assessment of three-dimensional bearing capacity of shallow foundation using fuzzy set theory," Frontiers of Structural and Civil Engineering, vol. 15, pp. 1-12, 2021.

[4] H. Hamidane, C. Alaa, M. Ali, and A. Ayman, "Reliability analysis of corrosion initiation in reinforced concrete structures subjected to chlorides in presence of epistemic uncertainties," Structural Safety, vol. 86, pp. 1-12, 2020.

[5] W. Suh and M. P. Hunter, "Signal design for displaced leftturn intersection using Monte Carlo method," KSCE Journal of Civil Engineering, vol. 18, no. 4, pp. 1140-1149, 2014.

[6] M. Vahdani, M. Ghazavi, and M. Roustaei, "Measured and predicted durability and mechanical properties of frozenthawed fine soils," KSCE Journal of Civil Engineering, vol. 24, no. 3, pp. $740-751,2020$.

[7] O. C. Zienkiewicz, C. Humpheson, and R. W. Lewis, "Associated and non-associated visco-plasticity and plasticity in soil mechanics," Géotechnique, vol. 25, no. 4, pp. 671-689, 1975.

[8] E. M. Dawson, W. H. Roth, and A. Drescher, "Slope stability analysis by strength reduction," Géotechnique, vol. 49, no. 6, pp. 835-840, 1999.

[9] K. Ugai and D. Leshchinsky, "Three-dimensional limit equilibrium and finite element analyses: a comparison of results," Soils and Foundations, vol. 35, no. 4, pp. 1-7, 1995.

[10] L. A. Zadeh, "Fuzzy sets," Information and Control, vol. 8, no. 3, pp. 338-353, 1965. 